\title{
S100 $\beta$ Interaction with Tau Is Promoted by Zinc and Inhibited by Hyperphosphorylation in Alzheimer's Disease
}

\author{
W. Haung Yu, ${ }^{1,2}$ and Paul E. Fraser ${ }^{1,3}$ \\ ${ }^{1}$ Centre for Research in Neurodegenerative Diseases, ${ }^{2}$ Department of Pharmacology, and ${ }^{3}$ Department of Medical \\ Biophysics, University of Toronto, Toronto, Ontario, Canada M5S 3H2
}

The zinc-binding protein $\mathrm{S} 100 \beta$ has been identified as an interacting partner with the microtubule-associated protein tau. Both proteins are individually affected in Alzheimer's disease (AD). $\mathrm{S} 100 \beta$, is overexpressed in the disease, whereas hyperphosphorylated tau constitutes the primary component of neurofibrillary tangles. In this study, we examine factors that modulate their binding and the potential role the complex may play in AD pathogenesis. Zinc was identified as a critical component in the binding process and a primary modulator of $\mathrm{S} 100 \beta$ associated cellular responses. Abnormally phosphorylated tau extracted from AD tissue displayed a dramatically reduced capacity to bind $\mathrm{S} 100 \beta$, which was restored by pretreatment with alkaline phosphatase. In differentiated SH-SY5Y cells, exogenous $\mathrm{S} 100 \beta$ was internalized and colocalized with tau con-

$\mathrm{S} 100 \beta$ is a small molecular weight $(10 \mathrm{kDa})$ zinc-calcium binding protein produced by astrocytes (Donato, 1991; Mrak et al., 1995). In addition to metal binding, $\mathrm{S} 100 \beta$ has several functions that include a role in the cytokine cycle, inhibition of selected phosphokinases, including phosphokinase $\mathrm{C}$ (PKC), and the stimulation of neurite outgrowth (Kligman and Marshak, 1985; Baudier and Cole, 1988; Marshak and Pena 1992; Zimmer et al., 1995; Griffin et al., 1998; Heizmann and Cox, 1998). S100 $\beta$ is located on chromosome 21 and is increased in Down's syndrome and Alzheimer's disease (by as much as 20-fold) (Griffin et al., 1989, 1998; Marshak et al., 1992; Castets et al., 1997). In AD, the pathology is defined by amyloid plaques and neurofibrillary tangles (NFT) that are accompanied by neuronal loss and aberrant neuritic sprouting (Masilah et al., 1991). The neuritic response may be induced by the loss of neuronal connections or a cellular reaction to amyloid deposition (Mrak et al., 1996). S100 $\beta$ overexpression in $\mathrm{AD}$ has been directly correlated with plaque-associated dystrophic neurite development and the astrocyte activation, as well as $\mathrm{S} 100 \beta$ overproduction, may be a direct effect of the loss of neuronal connections and amyloid- $\beta$ deposition (Van Eldik and Griffin, 1994; Mrak et al., 1996; Sheng et al., 2000). S100 $\beta$ levels are elevated in brain regions with a direct relationship to the presence of neuritic plaques (Sheng et al., 1994). In addition, astrocyte activation and $\mathrm{S} 100 \beta$ expression may also be correlated with neurofibrillary tangle formation in AD (Sheng et al., 1994).

Received Nov. 15, 2000; revised Jan. 11, 2001; accepted Jan. 18, 2001.

This work was supported by the Medical Research Council of Canada, Ontario Mental Health Foundation, and the Alzheimer Society of Ontario. W.H.Y. is supported by an Alzheimer's Society of Canada Doctoral Award.

Correspondence should be addressed to Haung $\mathrm{Yu}$, Centre for Research in Neurodegenerative Diseases, 6 Queen's Park Crescent West, University of Toronto, Toronto, Ontario, Canada M5S 3H2. E-mail: haung.yu@utoronto.ca.

Copyright (C) 2001 Society for Neuroscience 0270-6474/01/212240-07\$15.00/0 sistent with an intracellular association. This was enhanced by the addition of zinc and eliminated by divalent metal chelators. $\mathrm{S} 100 \beta$ uptake was also accompanied by extensive neurite outgrowth that may be mediated by its interaction with tau. S100 $\beta$-tau binding may represent a key pathway for neurite development, possibly through $\mathrm{S} 100 \beta$ modulation of tau phosphorylation and/or functional stabilization of microtubules and process formation. $\mathrm{S} 100 \beta$-tau interaction may be disrupted by hyperphosphorylation and/or imbalances in zinc metabolism, and this may contribute to the neurite dystrophy associated with $A D$.

Key words: S100ß; tau; Alzheimer's disease; zinc; binding; colocalization; neuronal development

This study examines the relationship between tau and $\mathrm{S} 100 \beta$ based on the observation that they are cellular binding partners and each may therefore regulate specific neurite outgrowth or tau hyperphosphorylation activity (Baudier and Cole, 1988; Sorci et al., 2000). Second, tau is a unique neuronal component that stabilizes microtubules leading to the formation of axonal processes and, in its hyperphosphorylated state, tau is the major component of neurofibrillary tangles (Su et al., 1994; Nagy et al., 1995; Ikura et al., 1998; Mailliot et al., 1998). Finally, although the mechanism is unknown, $\mathrm{S} 100 \beta$ can induce a similar neurite outgrowth that may be related to its association with tau. S100 $\beta$ has been shown to directly affect tau, for example, by its ability to block PKC phosphorylation at specific sites (Ser 262 and 313) (Biernat et al., 1992; Lin et al., 1994; Singh et al., 1996a). This activity may have a direct consequence for AD because loss of PKC phosphorylation increases the susceptibility of tau to hyperphosphorylation by GSK-3 $\beta$ (Singh et al., 1996b; Tsujo et al., 2000). This AD-related phosphorylation is considered to be a major factor in tau deposition and neurofibrillary degeneration (Su et al., 1994; Friedhoff et al., 1998; Ikura et al., 1998; Mailliot et al., 1998).

We have examined $\mathrm{S} 100 \beta$ binding proteins by affinity chromatography and immunoprecipitation to survey the potential involvement of other $\mathrm{AD}$-associated proteins. In addition to tau, $\mathrm{S} 100 \beta$ binding to the amyloid precursor protein (APP), the amyloid- $\beta$ peptide, and the presenilins (PS1 and PS2) were also assessed. Among the proteins we evaluated, tau was the only significant binding protein and furthermore, based on immunofluorescence studies, colocalized with $\mathrm{S} 100 \beta$ after internalization by neuronal cells. Zinc has also been implicated in some aspects of AD pathology, such as promotion of amyloid fibril formation (Bush et al., 1994) and, when examined in the current system, it 
significantly affected the relationship between $\mathrm{S} 100 \beta$ and tau. This may be attributable to zinc-induced conformational changes that result in the exposure of a hydrophobic domain and could represent a key site for tau binding (Fujii et al., 1986; Baudier and Cole, 1988; Baudier et al., 1992). In addition, changes to tau also regulated this interaction, as shown by the altered binding of S100 $\beta$ to the AD-related hyperphosphorylated NFT-tau. Based on our observations, S100 $\beta$-tau binding, overexpression of S100 $\beta$, and tau hyperphosphorylation in Alzheimer's disease pathology suggest that S100 $\beta$-tau interactions may contribute to neuronal development as well as neuronal dysfunction.

\section{MATERIALS AND METHODS}

Purification of $S 100 \beta$. Extracts containing $\mathrm{S} 100 \beta$ were prepared from fresh bovine brains using the method described by Isobe et al. (1977). A $20 \%$ homogenate was made in a potassium phosphate buffer $(0.1 \mathrm{M}$ $\mathrm{KPO}_{4}, \mathrm{pH} 7.1,1 \mathrm{~mm}$ EDTA, $1 \mu \mathrm{g} / \mathrm{ml}$ aprotinin, $1 \mu \mathrm{g} / \mathrm{ml}$ leupeptin, and $1 \mathrm{~mm}$ polymethonyl sulfate) with $2.66 \mathrm{M}$ (or $50 \%$ ) ammonium sulfate $\left(\mathrm{AmSO}_{4}\right)$. Cell debris was removed by centrifugation at $10,000 \times g$, and the supernatant was adjusted to $85 \% \mathrm{AmSO}_{4}$ at $\mathrm{pH} 4.2$ and incubated at $4^{\circ} \mathrm{C}$ for $2 \mathrm{hr}$. Precipitated proteins were recovered by centrifugation, dialyzed against phosphate buffer, and stored at $-20^{\circ} \mathrm{C}$ in lyophilized form. From this crude material, $\mathrm{S} 100 \beta$ was purified using a modified method as described by Baudier et al. (1982). Crude extracts were dissolved in the elution buffer (50 mM Tris-Base, $\mathrm{pH} 7.4$ ) with $1 \mathrm{~mm} \mathrm{ZnSO}_{4}$ and applied to a Phenyl Sepharose $650 \mathrm{M}$ column (ToyoPearl, Montgomeryville, PA). S100 $\beta$ was eluted using a step gradient containing $300 \mathrm{~mm}$ $\mathrm{NaCl}, 0.25 \mathrm{~mm} \mathrm{ZnSO}_{4}$, or $2 \mathrm{~mm}$ EDTA. Protein purity was assessed by SDS-PAGE with Coomassie staining and by Western blotting with an S100 $\beta$ monoclonal antibody (clone SH-B1; Sigma, St. Louis, MO).

Electrophoresis and Western blotting. S100 $\beta(1 \mu \mathrm{g})$ was dissolved in Laemmli buffer and separated on a 10-20\% Tricine gel (Novex, Carlsbad, CA). Gels were either stained with $0.2 \%$ Coomassie blue reagent in $5 \%$ acetic acid, or transferred to a polyvinylidene difluoride membrane. The membrane was washed in Tris-buffered saline (200 mM Tris-base, $\mathrm{pH} 7.4,150 \mathrm{~mm} \mathrm{NaCl}$ ), blocked with skim milk and incubated overnight with the required antibody. Immunoreactive bands were identified with HRP-conjugated secondary antibodies and visualized using enhanced chemiluminescence (ECL; Amersham Pharmacia Biotech, Arlington Heights, IL) with film exposure.

S100 $\beta$ affinity chromatography and identification of binding proteins. Purified S100 $\beta$ was immobilized on AffiGel-10 (Bio-Rad, Hercules, CA) and equilibrated in $100 \mathrm{~mm}$ HEPES with $0.25 \mathrm{~mm} \mathrm{ZnSO}_{4}$. Immobilized $\mathrm{S} 100 \beta$ was incubated with a human brain tissue homogenate $(10 \% \mathrm{w} / \mathrm{v})$, and nonspecific binding proteins were removed by washing with the initial buffer. A high salt (100 mM HEPES, $1 \mathrm{~m} \mathrm{NaCl}, 0.25 \mathrm{~mm} \mathrm{ZnSO}_{4}$ ) wash was used to elute proteins with weak $\mathrm{S} 100 \beta$ interactions. Zincdependent binding proteins were subsequently eluted with $1 \mathrm{~mm}$ EDTA, and any remaining bound elements were removed with $1 \mathrm{M}$ urea. All samples were collected and dialyzed then stored at $-20^{\circ} \mathrm{C}$ in their lyophilized form. Eluted proteins were analyzed on 4-20\% Tricine gels (Novex) and examined by silver staining and by Western blotting. Antibodies corresponding to $\mathrm{S} 100 \beta$, amyloid- $\beta$ (clone $6 \mathrm{~F} / 3 \mathrm{D}$; Dako, Carpinteria, CA), tau (Dako), and a presenilin antisera (Yu et al., 1998) were used to determine if they were capable of binding to $\mathrm{S} 100 \beta$.

Formation of $S 100 \beta$ complexes with normal and $A D$ tau. $\mathrm{AD}$ and control brain were homogenized $(10 \% \mathrm{w} / \mathrm{v})$ in $0.1 \mathrm{M} \mathrm{KH}_{2} \mathrm{PO}_{4}, 2 \mathrm{~mm}$ EDTA, 2 mm EGTA, and protease inhibitors. Samples were centrifuged for $45 \mathrm{~min}$ at $20000 \times \mathrm{g}$, and the supernatant was fractionated using 35 and $55 \%$ ammonium sulfate to produce a tau-enriched fraction. Crude protein precipitates were resuspended in $20 \mathrm{~mm}$ Tris and $0.5 \mathrm{M} \mathrm{NaCl}, \mathrm{pH}$ 7.6, with protease inhibitors. Samples were boiled, centrifuged at $25,000 \times g$ for $30 \mathrm{~min}$, and control aliquots were collected. To assess the effects of phosphorylation on $\mathrm{S} 100 \beta$ binding, samples were also treated with alkaline phosphatase (Sigma) for $30 \mathrm{~min}$ at $37^{\circ} \mathrm{C}$. Binding of $\mathrm{S} 100 \beta$ with tau from these enriched samples was assessed by immunoprecipitation. Aliquots of the brain extracts (50 $\mu \mathrm{g}$ of total protein) were combined with $1 \mu \mathrm{g}$ of purified bovine $\mathrm{S} 100 \beta$ and $10 \mu \mathrm{l}$ of $\mathrm{S} 100 \beta$ monoclonal antibody. The mixture was incubated overnight at $4^{\circ} \mathrm{C}$ and the $\mathrm{S} 100 \beta$ containing complexes were recovered by immunoprecipitation by protein-G sepharose. Beads were washed with buffer containing $50 \mathrm{~mm}$ Tris with $150 \mathrm{~mm} \mathrm{NaCl}$ and $0.5 \% \mathrm{NP}-40$, and $\mathrm{S} 100 \beta$ with bound proteins

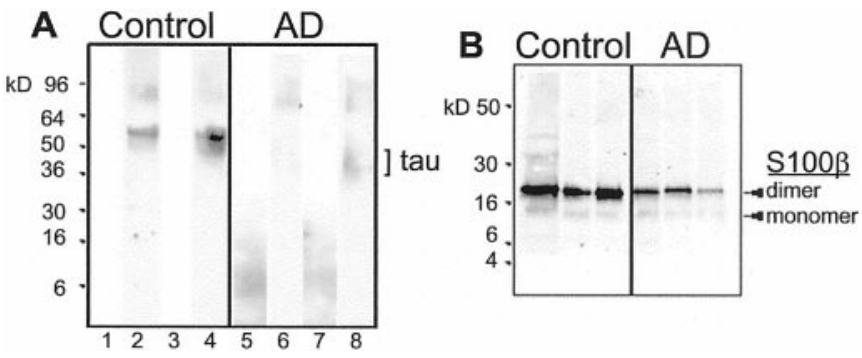

Figure 1. Affinity chromatography using immobilized $\mathrm{S} 100 \beta$ for identification of binding proteins $(A)$. Immunoblotting of zinc (lanes $1,3,5,7)$ and EDTA (lanes 2, 4, 6, 8)-eluted fractions indicated a significant amount of S100 $\beta$-associated tau in control samples from both frontal (lanes 1,2) and temporal cortices (lanes 3, 4). Comparable affinity analysis with AD-extracted proteins from frontal (lanes 5, 6) or temporal (lanes 7, 8) cortex indicated only weak tau immunoreactivity consistent with a reduced interaction with S100 $\beta$. Zinc-treated samples did not elute any proteins with tau immunoreactivity. Immunoblotting of total brain homogenates from $\mathrm{AD}$ and control indicating the elevated levels of $\mathrm{S} 100 \beta$, as has been previously demonstrated by Griffin et al. (1989) (B).

eluted with $500 \mathrm{~mm} \mathrm{NaCl}$ with $1 \mathrm{~mm}$ EDTA. Samples were collected, dialyzed, and examined by Western blotting using tau antibodies.

S100 $\beta$ internalization and subcellular distribution. Bovine S100 $\beta$ (final concentration, $5 \mu \mathrm{g} / \mathrm{ml}$ ) was added to culture and incubated for pulse of 4 or $24 \mathrm{hr}$. Cells were washed with fresh medium and harvested at 0,15 , 30 , or $60 \mathrm{~min}$ and 4,24 , or $48 \mathrm{hr}$. Cells lysates were examined by immunoblotting to determine cellular uptake of S100 $\beta$. SH-SY5Y cells were grown in $10 \%$ fetal bovine serum/DMEM (Life Technologies, Burlingame, $\mathrm{CA}$ ) at $37^{\circ} \mathrm{C}$ under $5 \% \mathrm{CO}_{2}$. Cells were placed on poly-Llysine-coated coverslips and differentiated using $10 \mu \mathrm{M}$ trans-retinoic acid. To examine colocalization with tau, $\mathrm{S} 100 \beta$ was preincubated with the cells for 4,12 , and $24 \mathrm{hr}$ under control conditions or with $50 \mu \mathrm{M}$ EDTA or $5 \mu \mathrm{M}$ EGTA for $1 \mathrm{hr}$ before addition of S100 $\beta$ or with $10 \mu \mathrm{g} / \mathrm{ml}$ $\mathrm{ZnSO}_{4}$. Cells were fixed with $2 \%$ paraformaldehyde and examined by immunofluorescence using a Nikon TE300 inverted microscope attached to a Bio-Rad Radiance 2000 laser confocal system.

\section{RESULTS}

\section{Identification and analysis of $S 100 \beta$ binding proteins}

Interactions of brain-derived proteins, such as tau, were initially examined by affinity chromatography using immobilized $\mathrm{S} 100 \beta$ as the primary substrate. A native $\mathrm{S} 100 \beta$ secondary structure was maintained in the presence of calcium and zinc to obtain physiologically relevant conditions for the evaluation of binding proteins (Baudier et al., 1982). A series of increasing elution stringencies were used to determine the relative affinities of $\mathrm{S} 100 \beta$ binding proteins. Proteins that failed to bind to the $S 100 \beta$ substrate were recovered in the initial wash. This was followed by a high salt elution to isolate proteins with weak ionic binding properties. High-affinity S100 $\beta$-associated proteins were removed by the addition of zinc chelators, which caused a structural rearrangement of S100 $\beta$. Previous studies have shown that zinc exposes a hydrophobic domain, which represents a potential binding site for its cellular partners (Isobe et al., 1977). Finally, any remaining proteins bound to the affinity column were removed with a denaturing urea wash, and each of these fractions was examined by direct silver staining as well as Western blotting.

Immunoblotting of the various elutions demonstrated that tau constituted a principal S100 $\beta$ binding protein. All other ADrelated proteins such as APP, amyloid- $\beta$, PS1, and PS 2 did not show any significant S100 $\beta$ binding and were recovered in the initial elution. Tau binding was particularly evident in the samples obtained from control cases in which strong signals were observed for all brain regions (Fig. $1 A$ ). The control tau was only eluted 
after zinc chelation with EDTA, suggesting that the observed conformation changes are important for binding. In contrast, in the comparable elutions, there was a marked decrease in the amount from the $\mathrm{AD}$ tau fraction (Fig. $1 A$ ). The lack of tau was not attributable to loss of immunoreactivity caused by changes in the AD-related protein because a polyclonal, nonphosphorylationdependent antibody was used. To confirm this, additional antisera were used (e.g., phosphorylation epitopes detected by the antibody AT8), which demonstrated a similar lack of tau binding. Examination of the complete range of elutions revealed that AD-tau was found in both the flowthrough and salt washes. Based on this finding, it was determined that tau from AD samples had a significantly lower affinity for $\mathrm{S} 100 \beta$.

To examine potential changes in the $S 100 \beta$ levels between AD and control cases, Western blotting of comparable tissue samples was investigated. In the AD cases that showed the loss of tau binding to $\mathrm{S} 100 \beta$, appreciable increases in the $\mathrm{S} 100 \beta$ levels were observed in all AD brain samples (Fig. $1 B$ ). The reason for the increased expression is unclear but does suggest an imbalance in S100 $\beta$ levels that may represent a compensatory mechanism for reduced activity. For example, if $\mathrm{S} 100 \beta$ does modulate tau function and/or metabolism, then the loss of this interaction in AD may induce the elevated expression.

\section{Identification of $\mathbf{S 1 0 0 \beta}$ and tau complex}

To assess further the binding of $\mathrm{S} 100 \beta$ to tau, immunoprecipitation of in vitro complexes was examined using both $\mathrm{AD}$ and control extracted samples. To accomplish this, a tau-enriched fraction was obtained from the brain homogenates through ammonium sulfate precipitation and incubated with purified S100 $\beta$. The effects of tau phosphorylation on S100 $\beta$-tau binding were also examined by immunoprecipitation with untreated extracts as well as after incubation with alkaline phosphatase. Because ADtau is heavily phosphorylated, this may be one reason for the observed reduction in its binding to $\mathrm{S} 100 \beta$.

Immunoprecipitation of untreated $\mathrm{AD}$ extracts using an antiS100 $\beta$ antibody yielded very low or undetectable levels of associated tau in all tissues examined (Fig. 2). This finding is consistent with the affinity chromatography results and suggests an impaired binding. In contrast, similar immunoprecipitation control samples produced a robust level of binding of tau to $\mathrm{S} 100 \beta$. The high level of tau immunoreactivity reflects the amount of binding to $\mathrm{S} 100 \beta$ in immunoprecipitation samples relative to the same amount of protein used in the AD samples. The formation of the S100 $\beta$-tau complex in the control extracts was also zinc-dependent. This event was demonstrated by the removal of zinc with EDTA, followed by the subsequent release of tau from immunoprecipitated $\mathrm{S} 100 \beta$. This observation is consistent with the elution profile from the affinity column, which facilitated the removal of tau from the immobilized S100 $\beta$. Dephosphorylation of tau by alkaline phosphatase restored the normal, possibly functional, binding of tau to $\mathrm{S} 100 \beta$ (Fig. 2). In all AD cases, we observed a significantly higher level of binding after tau dephosphorylation. There was little or no change in the amount of tau that could be immunoprecipitated in the comparable control samples after alkaline phosphatase treatment. Restoration of binding after dephosphorylation of tau indicates a possible mechanism for the lack of S100 $\beta$-tau interaction in the AD cases.

\section{Internalization and subcellular distribution of $S 100 \beta$ in neuronal cells}

S100 $\beta$ has a stimulatory activity on neurite outgrowth that may result from metal influx (calcium), cytokine activation, and acti-

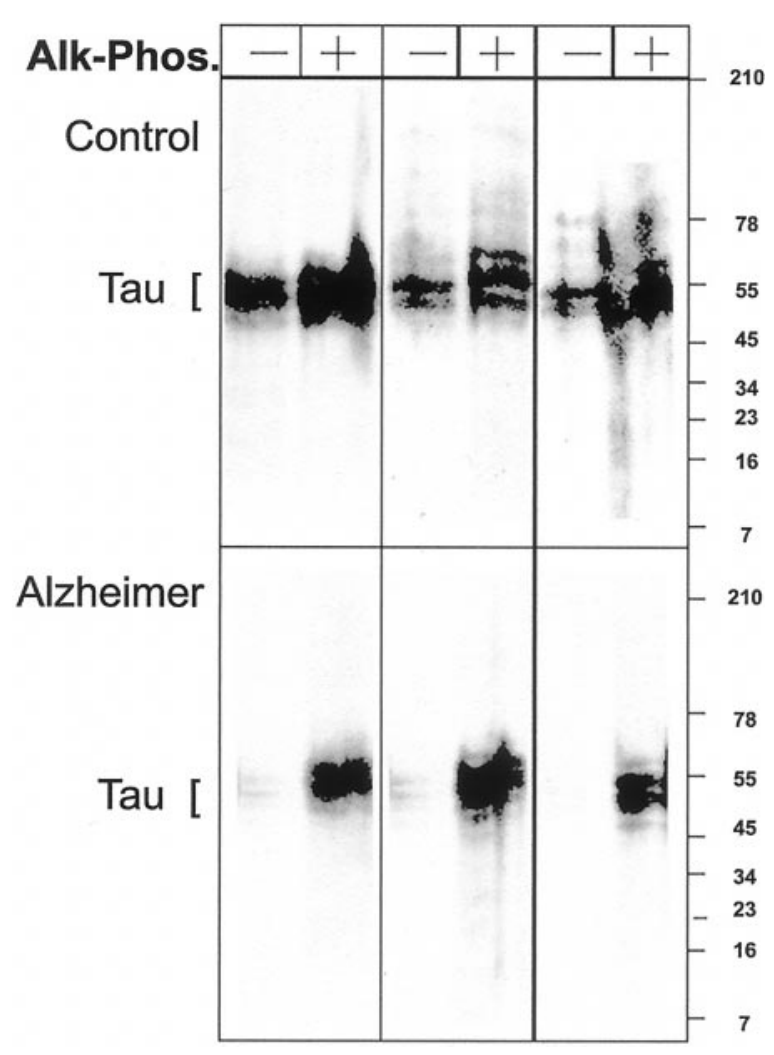

Figure 2. Immunoprecipitation of $\mathrm{S} 100 \beta$ complexed with brain-extracted tau from control and AD cases ( 3 separate tissue samples). Purified S100 $\beta$ incubated with tau-enriched and precipitated with an $\mathrm{S} 100 \beta$ polyclonal antibody indicated significant interacted evidenced by the coprecipitating tau. Untreated AD extracts displayed reduced tau binding to $\mathrm{S} 100 \beta$ under comparable conditions. The association was restored by dephosphorylation of the tau-containing extracts using alkaline phosphatase (Alk-Phos.).

vation of phosphokinases to initiate axonal growth or microtubule stabilization (Baudier et al., 1987a, 1988; Baudier and Cole, 1988; Lin et al., 1994; Sheu et al., 1994; Mrak et al., 1996; Sheng et al., 1996). One possibility that we explored was the direct uptake of exogenous S100 $\beta$ by neuronal cell lines and the effects of this internalization on tau. Purified $\mathrm{S} 100 \beta$ was added to cultures of SH-SY5Y cells and was pulsed for 4 or $24 \mathrm{hr}$ and then removed from the medium. Examination of cell lysates for $S 100 \beta$ indicated that after $4 \mathrm{hr}$ of incubation relatively low levels of the $\mathrm{S} 100 \beta$ dimer were observed (Fig. 3). When examined after different incubation times ( 4 and $24 \mathrm{hr}$ ), the amount of S100 $\beta$ slowly decreased with a significant reduction observed at $4 \mathrm{hr}$ and a complete loss of cell-associated protein at $24 \mathrm{hr}$. Incubation for a $24 \mathrm{hr}$ period resulted in substantially greater amounts of $\mathrm{S} 100 \beta$ in the cell lysates, including both monomeric and dimeric forms (Fig. 3). These levels were maintained $4 \mathrm{hr}$ after incubation and were detectable, but at reduced levels, and they were not observed after a $24 \mathrm{hr}$ clearance period. These observations indicate that significant quantities of $\mathrm{S} 100 \beta$ associate with the cells and are maintained over long periods of time.

It is unclear from the Western blotting data whether the $\mathrm{S} 100 \beta$ merely accumulates via nonspecific binding to the plasma membrane or if the cells are capable of internalizing the exogenous protein. To resolve this issue, retinoic acid differentiated $\mathrm{SH}$ SY5Y cells were used to produce a neuronal-like phenotype and the distribution of $\mathrm{S} 100 \beta$ examined by immunofluorescence. Cells incubated with purified bovine $\mathrm{S} 100 \beta$ displayed modest 


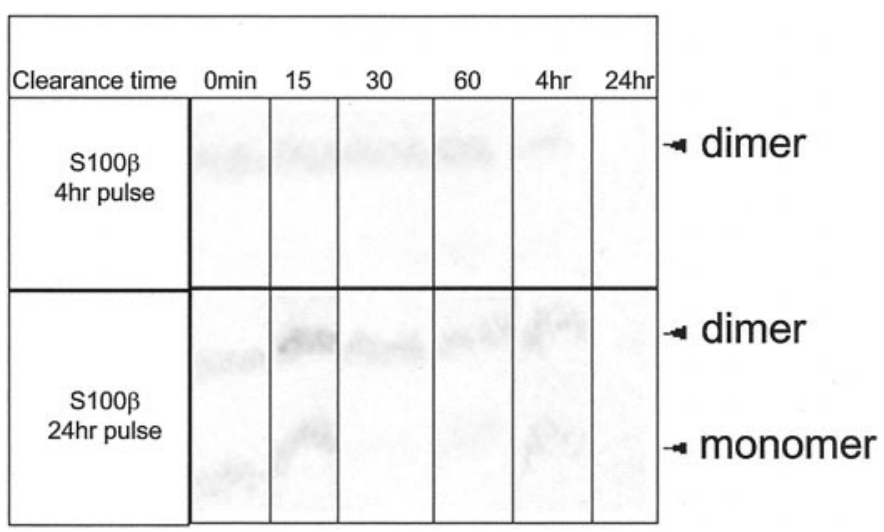

Figure 3. Time course of $\mathrm{S} 100 \beta$ internalization and clearance from differentiated SH-SY5Y neuroblastoma cells that were preincubated with $\mathrm{S} 100 \beta$ for 4 or $24 \mathrm{hr}$. Lysates were examined at different time points $(0,15$, 30 , and $60 \mathrm{~min}$ and 4 and $24 \mathrm{hr}$ ) after the removal of $\mathrm{S} 100 \beta$ from the culture medium. Readily detectable S100 $\beta$ (monomeric and dimeric forms) were observed after the $24 \mathrm{hr}$ pulse and to a lesser extent after 4 hr preincubation.
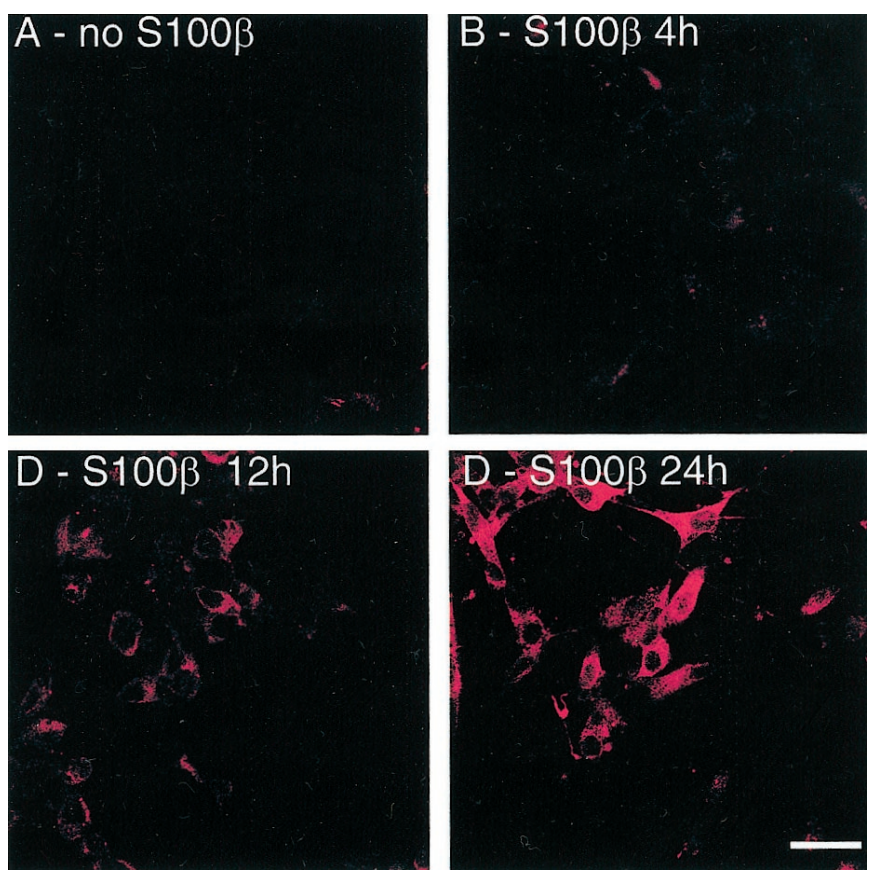

Figure 4. Immunofluorescence of SH-SY5Y cells that were preincubated with $\mathrm{S} 100 \beta$ for various lengths of time. Untreated cells displayed very low levels of $\mathrm{S} 100 \beta(A)$, which were increased after addition of $\mathrm{S} 100 \beta$ to the medium and incubations for $4(B)$ and $12 \mathrm{hr}(C)$. The $\mathrm{S} 100 \beta$ levels were significantly increased after $24 \mathrm{hr}$ of incubation $(D)$. S100 $\beta$ was distributed within the cell body and processes consistent with the internalization of the protein rather than cell surface association. Scale bar, $10 \mu \mathrm{m}$.

amounts of intracellular S100 $\beta$ staining after exposures for 4 and $12 \mathrm{hr}$ (Fig. 4). Consistent with the Western blotting data, substantial levels of $\mathrm{S} 100 \beta$ were found after the $24 \mathrm{hr}$ incubation (Fig. $4 D$ ). $\mathrm{S} 100 \beta$ immunoreactivity was distributed within the cell body and extended into the processes but was absent from the nuclear region.

The degree of S100 $\beta$ internalization was also affected by zinc, as shown by the increased level of staining within cells, as compared with control, when zinc was added to the medium and coincubated for $24 \mathrm{hr}$ (Fig. 5). The effect of zinc (and possibly
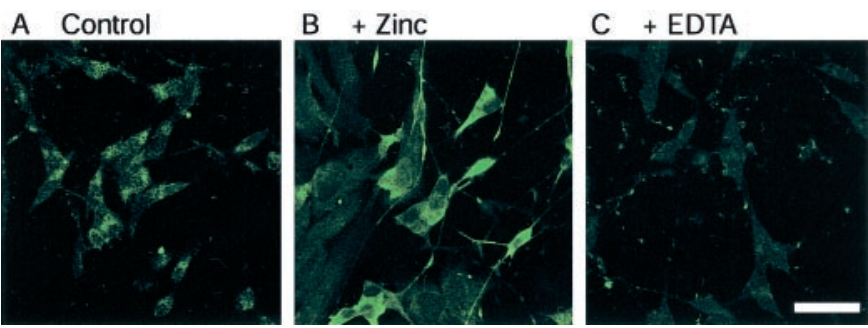

Figure 5. Immunofluorescence of differentiated SH-SY5Y cells demonstrating the effects of zinc on $\mathrm{S} 100 \beta$ internalization. Samples exposed to untreated $\mathrm{S} 100 \beta$ showed an easily detectable level of protein uptake at $24 \mathrm{hr}(A)$. Elevation of the culture medium zinc concentration to $10 \mu \mathrm{M}$ resulted in a substantial increase in the intracellular $\mathrm{S} 100 \beta$ levels $(B)$. This zinc-induced enhancement of $\mathrm{S} 100 \beta$ internalization could be reversed with addition of metal chelators such as EDTA $(C)$. Scale bar, $10 \mu \mathrm{m}$.

other divalent metals) was supported by EDTA treatment that has a higher affinity for the metal as compared with $\mathrm{S} 100 \beta$. Under these metal-depleted conditions, the level of $\mathrm{S} 100 \beta$ was markedly reduced in the SH-SY5Y cultures as compared with controls (Fig. $5 C$ ). To examine the effects of other divalent cations, the calciumspecific chelator EGTA was added to our cultures to block free and extracellular calcium. Low EGTA concentrations were used because they were not toxic and do not block neuritic sprouting but were sufficient to bind a significant proportion of free calcium. EGTA-treated cells exhibited comparable S100 $\beta$ staining, providing additional support for the specific role of zinc (data not shown). Cumulatively, the Western blotting and immunofluorescence studies suggest that $\mathrm{S} 100 \beta$ is actively internalized by the cells as opposed to surface association. This uptake has a number of implications for the mechanism of $\mathrm{S} 100 \beta$ activity in neuronal systems and its possible relationship to tau function.

\section{Colocalization of $S 100 \beta$ with tau and enhanced neurite outgrowth}

To investigate the relationship between S100 $\beta$-tau binding and neurite outgrowth, differentiated SH-SY5Y cells were allowed to internalize $\mathrm{S} 100 \beta$, and its subcellular distribution with respect to tau was examined by immunofluorescence. Under control conditions, $\mathrm{S} 100 \beta$ was broadly distributed within the cell body and some processes. Furthermore, in the double-labeled cells, the staining overlaps to some degree with tau (Fig. 6A). However, a zinc-induced increase in the level of $\mathrm{S} 100 \beta$ within the cell produced a much more defined colocalization with tau. This is particularly evident within the processes in which the $\mathrm{S} 100 \beta$ and tau coincided as punctate staining that was observed in virtually all neurites (Fig. 6B, arrows). Colocalization of $\mathrm{S} 100 \beta$ was also time-dependent because $24 \mathrm{hr}$ of incubation produced higher levels of overlapping signals when compared with the 4 or $12 \mathrm{hr}$ samples. To ensure that there were no significant changes in tau, the $\mathrm{S} 100 \beta$-treated cells were also analyzed for changes in phosphorylation using the paired helical filament (PHF)-tau AT8 antibody. AT8 immunoreactivity was not detected in any of the treated cells, at any time points (data not shown). The effects of zinc and the enhanced colocalization may reflect simply an increased cellular uptake of $\mathrm{S} 100 \beta$, or metal binding may promote a preferred conformation that facilitates tau binding. This latter possibility would be consistent with our affinity chromatography and immunoprecipitation results. These findings suggest that internalized $\mathrm{S} 100 \beta$ may be associated with tau and thereby affect tau function and/or metabolic events such as phosphorylation. 


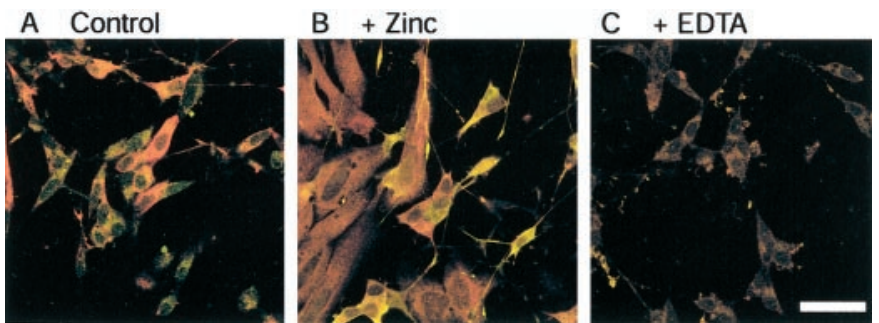

Figure 6. Colocalization of internalized $\mathrm{S} 100 \beta$ with tau in differentiated neuroblastoma cells. Under control conditions, S100 $\beta$ (red) that was taken up by the cells showed partial overlap with tau (green), suggesting a possible intracellular association $(A)$. The colocalization was more pronounced with the addition of zinc to the culture medium $(B)$. Zinc elevated levels of $\mathrm{S} 100 \beta$ resulted in increased neurite outgrowth and frequent overlap of $\mathrm{S} 100 \beta$ with tau in these processes, which appear as discrete, punctate staining within the cell processes $(B)$. Addition of EDTA to the culture medium before incubation of the cells with S100 $\beta$ eliminated the tau colocalization pattern caused by reduced protein uptake $(C)$. Scale bar, $10 \mu \mathrm{m}$.
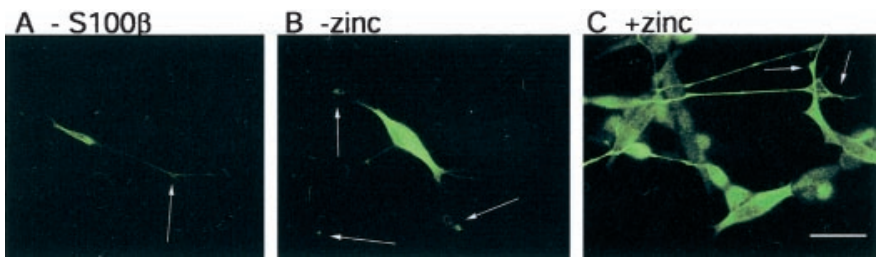

Figure 7. Stimulation of neurite outgrowth in SH-SY5Y cells after S100 $\beta$ internalization. Retinoic acid differentiated cells displayed a neuron-like morphology but with only a limited number of extensions $(A$, arrow). With the addition of untreated $\mathrm{S} 100 \beta$, the number and length of the processes were enhanced $(B)$. Addition of zinc to the medium and the accompanying increase in $\mathrm{S} 100 \beta$ uptake resulted in widespread increase in neurite outgrowth, leading to the formation of dense networks of cell processes $(C)$. Cells and processes were visualized by immunofluorescence staining of the cell surface cadherins. Scale bar, $10 \mu \mathrm{m}$.

Tau is one of the key elements that control axonal growth and may be modulated, to some degree, by interactions with $\mathrm{S} 100 \beta$. This hypothesis is supported in our experimental system by the response of the SH-SY5Y cells to S100 $\beta$ and zinc. Even with retinoic acid differentiation, SH-SY5Y cells do not produce extensive process formation and have a predominantly "spindle-type" morphology (Fig. 7A). With the addition of $\mathrm{S} 100 \beta$, a greater number of neurites were observed when visualized using an antibody staining for cadherins on the cell surface (Fig. 7B). Neurite outgrowth was even more pronounced in the presence of zinc in which enhanced $\mathrm{S} 100 \beta$ uptake resulted in increased number of neurites with extensive outgrowth that produced both longer networks of processes (Fig. 7C). Under these conditions, abnormal neuritic sprouting was also observed with processes emanating from the cell body. Stimulation of neurites and colocalization of $\mathrm{S} 100 \beta$ with tau provides additional evidence for a physiological role for their interaction.

\section{DISCUSSION}

These studies were performed to establish the binding of $\mathrm{S} 100 \beta$ to tau and the chemical properties involved, as well as identify its relevance to Alzheimer's disease. Our findings demonstrate that $\mathrm{S} 100 \beta$ binds to tau. In addition, this interaction is enhanced by zinc and inhibited by tau hyperphosphorylation. The functional aspects of S100 $\beta$-tau binding may impact on several different pathways that are regulated by the two proteins. For example, S100 $\beta$ may provide a scaffolding structure for tau to stabilize microtubules and possibly contribute to the abnormal neuritic dystrophy that is observed in AD (Baudier and Cole, 1988; Tam, 1990; Azmitia et al., 1995). This is illustrated by our observation that nonphysiological sprouting of processes are from the cell body, which is not normally seen in differentiated neuronal cultures. The second possibility is that $\mathrm{S} 100 \beta$ is a modulator of tau phosphorylation and that any changes in their interaction could be a factor in the AD-related hyperphosphorylation, as has been previously suggested (Baudier et al., 1987a; Sorci et al., 2000). Furthermore, the ability of $\mathrm{S} 100 \beta$ to inhibit PKC may potentiate the aberrant phosphorylation at key sites [e.g., residues 262 and 313 (Correas et al., 1992; Singh et al., 1996b)]. However, in our in vitro studies, $\mathrm{S} 100 \beta$ did not appear to promote aberrant phosphorylation, as indicated by the lack of AT8 staining that identifies PHF-tau related phosphorylated epitopes (Biernat et al., 1992). Neuritic development, although beneficial in the short term to rejuvenate lost neuronal connections, can also be detrimental in the chronic stages of AD because it increases cellular metabolic requirements and exposes the neurons to external insults.

Initially, our finding that $\mathrm{S} 100 \beta$ failed to bind AD-derived tau was attributed to the reduced number of neurons, which is associated with the progression of AD. This did not appear to be the case because the normal binding could be restored after alkaline phosphatase treatments. Although this may suggest that all phosphate groups on tau hinder $\mathrm{S} 100 \beta$ binding, this is not evident because tau is naturally phosphorylated, and this does not affect binding of the control sample tau to $\mathrm{S} 100 \beta$. In these studies, it is only with abnormal hyperphosphorylation of tau present in AD that prevents S100 $\beta$-tau binding activity. Our study has also demonstrated that zinc is important factor in the internalization of $\mathrm{S} 100 \beta$ into neurons and enhances tau binding. In addition, we observed an increase in neuritic sprouting in SH-SY5Y cells treated with $\mathrm{S} 100 \beta$ and zinc, which suggests that metal binding may be critical to this outgrowth activity.

$\mathrm{S} 100 \beta$ has been demonstrated to have several biological functions in AD. This is reflected by its ability to bind zinc and calcium, as well as inhibit certain phosphorylation pathways. In addition, $\mathrm{S} 100 \beta$ has been shown to activate the complement pathway through interleukin-6 activation (Stanley et al., 1994; Mrak et al., 1995; Sheng et al., 1996a,b; Hays, 1998). S100 $\beta$ itself is activated by interleukin-1 and may also participate in a positive feedback loop, thereby inducing its own production through the promotion of astrocytic activity (Mrak et al., 1995). In AD, the observed increase in $\mathrm{S} 100 \beta$ production appears to be related to some of the physiological changes associated with interleukins and to the increase in neuritic sprouting. The uptake of S100 $\beta$ may represent a key role in its ability to alter the neuronal activity. Our immunofluorescence data suggests that S100 $\beta$ uptake by cells is enhanced by the addition of zinc. As stated previously, zinc causes $\mathrm{S} 100 \beta$ to undergo a conformational change, exposing a hydrophobic domain that facilitates neuronal internalization. Within the cell, S100 $\beta$ may alter many cellular processes, including binding to tau.

The metal-binding capacity of $\mathrm{S} 100 \beta$ appears to be a crucial functional element and may have some bearing on other disease pathways. S100 $\beta$-calcium effects have been extensively examined by Baudier and Cole (1987a,b, 1988), in which they found evidence of $\mathrm{S} 100 \beta$-calcium binding to microtubule-associated proteins, including tau, and calcium-calmodulin-dependent protein 
kinase II. Calcium is also thought to be excitotoxic in AD (Kim et al., 2000). In AD, both calcium and zinc have been implicated in the amyloid toxicity pathway. Zinc, as well as copper, is believed to accelerate the formation of amyloid fibrils (Bush et al., 1994; Yang et al., 2000). Amyloid is implicated as a potential membrane protein that may promote the influx of calcium across the plasma membrane. The increase of S100 $\beta$ in AD may contribute to the shuttle of these metals to points of interaction, thereby accelerating the pathogenic process.

Zinc does not normally appear in the cell as a free, or unbound, form. It is believed to be toxic in this state. This may be related to the ability of free zinc to enter via AMPA channels (Sensi et al., 1997, 1999; Yin et al., 1998), promoting excitotoxicity. Proteins such as metallothionein and $\mathrm{S} 100 \beta$ are induced by astrocytes to compensate for the extrusion of zinc into the extracellular space to block its toxic effects. In the case of $\mathrm{S} 100 \beta$, the effect may detrimentally alter the disease process.

The role of zinc in AD has generated several interesting and pathogenically significant hypotheses. The potential role that it may play with $\mathrm{S} 100 \beta$ on the effect on neuritic sprouting is another important addition to this metals role in the disease process. Finally, our observations suggest that, in addition to its activation of cytokines, $\mathrm{S} 100 \beta$ may also play a more direct role in taurelated pathways that are associated with neurodegeneration in Alzheimer's disease.

\section{REFERENCES}

Azmitia EC, Rubinstein VJ, Strafaci JA, Rios JC, Whitaker-Azmitia PM (1995) 5-HT1A agonist and dexamethasone reversal of parachloroamphetamine induced loss of MAP-2 and synaptophysin immunoreactivity in adult rat brain. Brain Res 677:181-192.

Baudier J, Cole RD (1987a) Reinvestigation of the sulfhydryl reactivity in bovine brain S100b (beta beta) protein and the microtubuleassociated tau proteins. $\mathrm{Ca}^{2+}$ stimulates disulfide cross-linking between the S100b beta-subunit and the microtubule-associated tau(2) protein. Biochemistry 27:2728-2736.

Baudier J, Cole RD (1987b) Phosphorylation of tau proteins to a state like that in Alzheimer's brain is catalyzed by a calcium/calmodulindependent kinase and modulated by phospholipids. J Biol Chem 262:17577-17583.

Baudier J, Cole RD (1988) Interactions between the microtubuleassociated tau proteins and $\mathrm{S} 100 \mathrm{~b}$ regulate tau phosphorylation by the $\mathrm{Ca}^{2+}$ /calmodulin-dependent protein kinase II. J Biol Chem 263:5876-5883.

Baudier J, Briving C, Deinum J, Kaglid K, Sorskog L, Wallin M (1982) Effect of S100 proteins and calmodulin on $\mathrm{Ca}^{2+}$-induced disassembly of brain microtubule proteins in vitro. FEBS Lett 148:231-234.

Baudier J, Mochly-Rosen D, Newton A, Lee SH, Koshland Jr DE, Cole RD (1987) Comparison of S100b protein with calmodulin: interactions with mellitin and microtubule-associated tau proteins and inhibition of phosphorylation of tau proteins by protein kinase C. Biochemistry 26:2886-2893.

Baudier J, Delphin C, Grunwald D, Khochbin S, Lawrence JJ (1992) Characterization of the tumor suppressor protein p53 as a protein kinase C substrate and a S100b-binding protein. Proc Natl Acad Sci USA 89:1627-1631.

Biernat J, Mandelkow EM, Schroter C, Lichtenberg-Kraag B, Steiner B, Berling B, Meyer H, Mercken M, Vandermeen A, Goedert M (1992) The switch of tau protein to an Alzheimer-like state includes the phosphorylation of two serine-proline motifs upstream of the microtubule binding region. EMBO J 11:1593-1597.

Bush AI, Pettingell WH, Multhaup G, Paradis MD, Vonsattel J-P, Gusella JF, Beyreuther K, Masters CL, Tanzi RE (1994) Rapid induction of Alzheimer $\mathrm{A} \beta$ amyloid formation by zinc. Science 265:1464-1467.

Castets F, Griffin WS, Marks A, Van Eldik LJ (1997) Transcriptional regulation of the human S100 beta gene. Brain Res Mol Brain Res 46:208-216.

Correas I, Diaz-Nido J, Avila J (1992) Microtubule-associated protein tau is phosphorylated by protein kinase $\mathrm{C}$ on its tubulin binding domain. J Biol Chem 267:15721-15728.

Donato R (1991) Perspectives in S100 protein biology. Cell Calcium 12:713-726.

Friedhoff P, Schneider A, Mandelkow EM, Mandelkow E (1998) Rapid assembly of Alzheimer-like paired helical filaments from microtubule- associated protein tau monitored by fluorescence in solution. Biochemistry $37: 10223-10230$.

Fujii T, Gochou N, Akabane Y, Fujii M, Kondo Y, Suzuki T, Ohki K (1986) Effect of zinc ions on the interaction of S-100 protein with brain microtubule. Chem Pharm Bull 34:5040-5044.

Griffin WS, Stanley LC, Ling C, White L, MacLeod V, Perrot LJ, White III CL, Araoz C (1989) Brain interleukin 1 and S-100 immunoreactivity are elevated in Down syndrome and Alzheimer disease. Proc Natl Acad Sci USA 86:7611-7615.

Griffin WS, Sheng JG, McKenzie JE, Royston MC, Gentleman SM, Brumback RA, Cork LC, Del Bigio MR, Roberts GW, Mrak RE (1998) Life-long overexpression of S100beta in Down's syndrome: implications for Alzheimer pathogenesis. Neurobiol Aging 19:401-405.

Hays SJ (1998) Therapeutic approaches to the treatment of neuroinflammatory diseases. Curr Pharm Des 4:335-48.

Heizmann CW, Cox JA (1998) New perspectives on S100 proteins: a multif unctional $\mathrm{Ca}(2+)-, \mathrm{Zn}(2+)$ - and $\mathrm{Cu}(2+)$-binding protein family. Biometals 11:383-397.

Ikura Y, Kudo T, Tanaka T, Tanii H, Grundke-Iqbal I, Iqbal K, Takeda M (1998) Levels of tau phosphorylation at different sites in Alzheimer disease brain. NeuroReport 9:2375-2379.

Isobe T, Nakajima T, Okuyama T (1977) Reinvestigation of extremely acidic proteins in bovine brain. Biochim Biophys Acta 494:222-232.

Kim HS, Park CH, Cha SH, Lee JH, Lee S, Kim Y, Rah JC, Jeong SJ, Suh YH (2000) Carboxyl-terminal fragment of Alzheimer's APP destabilizes calcium homeostasis and renders neuronal cells vulnerable to excitotoxicity. FASEB J 14:1508-1517.

Kligman D, Marshak DR (1985) Purification and characterization of a neurite extension factor from bovine brain. Proc Natl Acad Sci USA 82:7136-7139.

Lin LH, Van Eldik LJ, Osheroff N, Norden JJ (1994) Inhibition of protein kinase $\mathrm{C}$ and casein kinase II-mediated phosphorylation of GAP-43 by S100 beta. Brain Res Mol Brain Res 25:297-304.

Mailliot C, Sergeant N, Bussiere T, Caillet-Boudin ML, Delacourte A, Buee L (1998) Phosphorylation of specific sets of tau isoforms reflects different neurofibrillary degeneration processes. FEBS Lett 433:101-104.

Marshak DR, Pena LA (1992) Potential role of S100 beta in Alzheimer's disease: an hypothesis involving mitotic protein kinases. Prog Clin Biol Res 379:289-307.

Marshak DR, Pesce SA, Stanley LC, Griffin WS (1992) Increased S100 beta neurotrophic activity in Alzheimer's disease temporal lobe. Neurobiol Aging 13:1-7.

Masilah E, Mallory M, Hansen L, Alford M, Albright T, DeTeresa R, Terry R, Baudier J, Saitoh T (1991) Patterns of aberrant sprouting in Alzheimer's disease. Neuron 6:729-739.

Mrak RE, Sheng JG, Griffin WS (1995) Glial cytokines in Alzheimer's disease: review and pathogenic implications. Hum Pathol 26:816-823.

Mrak RE, Sheng JG, Griffin WS (1996) Correlation of astrocytic S100 beta expression with dystrophic neurites in amyloid plaques of Alzheimer's disease. J Neuropathol Exp Neurol 55:273-279.

Nagy Z, Esiri MM, Jobst KA, Morris JH, King EM, McDonald B, Litchfield S, Smith A, Barnetson L, Smith AD (1995) Relative roles of plaques and tangles in the dementia of Alzheimer's disease: correlations using three sets of neuropathological criteria. Dementia 6:21-31.

Sensi SL, Canzoniero LM, Yu SP, Ying HS, Koh JY, Kerchner GA, Choi DW (1997) Measurement of intracellular free zinc in living cortical neurons: route of entry. J Neurosci 17:9554-9564.

Sensi SL, Yin HZ, Weiss H (1999) Glutamate triggers preferential $\mathrm{Zn}^{2+}$ flux through $\mathrm{Ca}^{2+}$ permeable AMPA channels and consequent ROS production. NeuroReport 10:1723-1727.

Sheng JG, Mrak RE, Griffin WS (1994) S100 beta protein expression in Alzheimer disease potential role in the pathogenesis of neuritic plaques. J Neurosci Res 39:398-404.

Sheng JG, Ito K, Skinner RD, Mrak RE, Rovnaghi CR, Van Eldik LJ, Griffin WS (1996a) In vivo and in vitro evidence supporting a role for the inflammatory cytokine interleukin-1 as a driving force in Alzheimer pathogenesis. Neurobiol Aging 17:761-766.

Sheng JG, Mrak RE, Rovnaghi CR, Kozlowska E, Van Eldik LJ, Griffin WS (1996b) Human brain S100 beta and S100 beta mRNA expression increases with age: pathogenic implications for Alzheimer's disease. Neurobiol Aging 17:359-363.

Sheng JG, Mrak RE, Bales KR, Cordell B, Paul SM, Jones RA, Woodward S, Zhou XQ, McGinness JM, Griffin WS (2000) Overexpression of the neuritotrophic cytokine S100beta precedes the appearance of neuritic beta amyloid plaques in APPV717F mice. J Neurochem 74:295-301.

Sheu FS, Azmitia EC, Marshak DR, Parker PJ, Routtenberg A (1994) Glial-derived S100b protein selectively inhibits recombinant beta protein kinase $\mathrm{C}$ (PKC) phosphorylation of neuron-specific protein F1/ GAP43. Brain Res Mol Brain Res 21:62-66.

Singh TJ, Wang JZ, Novak M, Kontzekova E, Grundke-Iqbal I, Iqbal K (1996a) Calcium/calmodulin-dependent protein kinase II phosphorylates tau at Ser-262 but only partially inhibits its binding to microtubules. FEBS Lett 387:145-148. 
Singh TJ, Zaidi T, Grundke-Iqbal I, Iqbal K (1996b) Non-proline dependent protein kinases phosphorylate several sites found in tau from Alzheimer disease brain. Mol Cell Biochem 154:143-151.

Sorci G, Agneletti AL, Donato R (2000) Effects of S100 and S100B on microtubule stability. An in vitro study using triton-cytoskeletons from astrocyte and myoblast cell lines. Neuroscience 99:773-783.

Stanley LC, Mrak RE, Woody RC, Perrot LJ, Zhang S, Marshak DR, Nelson SJ, Griffin WS (1994) Glial cytokines as neuropathogenic factors in HIV infection: pathogenic similarities to Alzheimer's disease. J Neuropathol Exp Neurol 53:231-238.

$\mathrm{Su} \mathrm{JH}$, Cummings BJ, Cotman CW (1994) Early phosphorylation of tau in Alzheimer's disease occurs at Ser-202 and is preferentially located within neurites. NeuroReport 5:2358-2362.

Tam PK (1990) An immunohistological study of the human enteric nervous system with microtubule-associated proteins. Gastroenterology 99:1841-1844.

Tsujo I, Tanaka I, Kudo T, Nishikawa T, Shinozaki K, Grunde-Iqbal I, Iqbal K, Takeda M (2000) Inactivation of glycogen synthetase
kinase-3B by protein kinase $\mathrm{C}$ activation: implications for regulation of tau phosphorylation. FEBS Lett 469:111-117.

Van Eldik LJ, Griffin WS (1994) S100 beta expression in Alzheimer's disease: relation to neuropathology in brain regions. Biochim Biophys Acta 1223:398-403.

Yang DS, McLaurin J, Qin K, Westaway D, Fraser PE (2000) Examining the zinc binding site of amyloid- $\beta$ peptide. Eur J Biochem 267:1-7.

Yin HZ, Ha DH, Carriedo SG, Weiss JH (1998) Kainate-stimulated $\mathrm{Zn}^{2+}$ uptake labels cortical neurons with $\mathrm{Ca}^{2+}$-permeable AMPA/ kainate channels. Brain Res 781:45-55.

Yu G, Chen F, Levesque G, Nishimura M, Zhang DM, Levesque L, Rogaeva E, Xu D, Liang Y, Duthie M, St. George-Hyslop PH, Fraser PE (1998) The presenilin 1 protein is a component of a high molecular weight intracellular complex that contains beta-catenin. J Biol Chem 273:16470-16475.

Zimmer DB, Cornwall H, Landar A, Song W (1995) The S100 protein family: history, function, and expression. Brain Res Bull 37:417-429. 